\title{
Feasibility analysis of $100 \%$ tire pyrolysis oil in a common rail Diesel engine
}

\author{
Urban Žvar Baškoviča,*, Rok Vihar ${ }^{b}$, Tine Seljak $^{c}$ and Tomaž Katrašnik ${ }^{d}$ \\ a,* Corresponding author. Faculty of Mechanical Engineering, Ljubljana, Slovenia, urban.zvar- \\ baskovic@fs.uni-lj.si \\ ${ }^{b}$ Faculty of Mechanical Engineering, Ljubljana, Slovenia, rok.vihar@fs.uni-lj.si \\ ${ }^{c}$ Faculty of Mechanical Engineering, Ljubljana, Slovenia, tine.seljak@fs.uni-lj.si \\ ${ }^{d}$ Faculty of Mechanical Engineering, Ljubljana, Slovenia, tomaz.katrasnik@fs.uni-lj.si
}

\begin{abstract}
Tire pyrolysis oil (TPO) represents a promising waste-derived fuel for Diesel engines with its main deficiency being lower cetane number compared to Diesel fuel. Until now, successful utilization of the TPO in Diesel engines was possible only by increasing its cetane number, increasing compression ratio of the engine or preheating intake air or operation. This study shows the foremost results of utilizing the pure TPO in a modern turbocharged and intercooled Diesel engine without any of the aforementioned aids, which significantly facilitates its use and boosts its conversion efficiency to mechanical work. This was achieved by the tailored injection strategy that includes pilot injection, which was previously not utilized in combination with the TPO. The study reveals that with additional tailoring of the pilot injection, further optimization of thermodynamic parameters can be achieved while operating the turbocharged and intercooled Diesel engine in a wide operating range under the use of pure TPO. Discovered phenomena are supported by interpretation of interactions between the injection parameters and combustion as well as emission formation phenomena of the pure TPO.
\end{abstract}

\section{Keywords}

Tire pyrolysis oil, Diesel engines, Injection strategy, Thermodynamic parameters, Emissions.

\section{Introduction}

Internal combustion engines are widespread both in transport as well as in stationary systems for electricity generation, and it is commonly accepted that they will stay in commercial use as a main power source for another 20 years [1]. Increasing engine efficiency, along with lowering exhaust emissions has been the main objective of engine manufacturers to lower their environment impact. In addition, the search for alternative sources of energy to power internal combustion engines continues because of reduction of fossil oil reserves. In the past, significant attention was given to use of fatty acid methyl esters [2-6], oxygenated fuel blends [7] and numerous blends with conventional fuels (Diesel, gasoline) [8-10]. Additionally products of gasification were utilized in internal combustion engines [11,12]. Furthermore, the growing problem of disposal of slowly degradable waste, among which car tires represent a big portion, makes waste-to-fuel technologies a logical step towards alternative fuels.

\subsection{Energy recovery from waste tires}

European Automotive Manufacturers Association estimates that there are approximately 1.35 billion vehicles on the roads worldwide [13], which considering that each has 4 tires results in approximately 5.5 billion tires being used worldwide. An average car tire life span can be considered to be five years [14] and therefore it can be concluded that more than 1 billion waste car tires are generated annually. To reduce environment pollution, a recycling process is highly desirable Furthermore, a high calorific value (35-40 MJ/kg) [15] as well as a considerable 
amount of carbon black in used vehicle tires rubber stand out as being a good feedstock for fuel production.

Several conversion processes have been developed to transform solid waste disposals into liquid fuels which have similar physical characteristics to conventional automotive fuels and could therefore be used in the conventional engines with small adaptations of the engine control. Nowadays, tire recycling pyrolysis methods can be considered as methods that are receiving the most attention, as they can be seen as an environmentally acceptable and efficient way of tire disposal [16]. Among them, for conversion of waste vehicle tires, the most suitable pyrolysis subtype is vacuum pyrolysis [17]. Different studies utilized different temperatures and other process conditions, such as residence time, pressure, and tire particle and feedstock composition to perform de-polymerization of vehicle tires in an inert atmosphere, which had the influence on the ratio between product, consisting of incondensable gasses, tire pyrolysis oil (TPO) and char. However, process conditions can be optimized to favour either of the products [18]. It was found out that the maximum recovery of oil was obtained at $415^{\circ} \mathrm{C}$ [19].

\subsection{Current approaches to utilization of the TPO in Diesel engines}

Diesel - compression ignition (CI) - engines stand out as being potential power plants for the use of TPO, although either fuel properties or engine operation parameters should be optimized to allow for stable combustion and comparable performance and emissions to Diesel fuel (D2) operation. Current approach to successful operation of Diesel engines with TPO mainly relies on the following strategies (Fig. 1):

- Blending of TPO with other fuels. Some analyses [20,21] indicate that, because of its low cetane number, TPO should be blended with D2 or complemented by a cetane improver, such as diethyl ether, for application in Diesel engines. Consequently, many studies using TPO blended with Diesel fuel [15,16,20,22-25] or methyl esters $[26,27,10]$ are found in the literature. Results indicate that reliable operation of Diesel engine can be achieved up to $70 \%$ of the TPO in the Diesel blend [28].

- Increasing intake air temperature. Some studies suggest that increasing the intake air temperature above threshold which is in case of TPO $145^{\circ} \mathrm{C}$ is also a suitable measure [29]. This temperature rise was achieved through an external heater used for preheating intake air, which lowers the total energy efficiency and applicability of the system. Intake air preheating can be omitted in case of turbocharged engines, where bypassing intercooler results in sufficiently high temperatures to yield the same effect as intake air preheating. Bypassing intercooler also results in higher temperature levels and thus temperature loadings components as well as in lower engine efficiency and higher nitrous oxides $\left(\mathrm{NO}_{\mathrm{x}}\right)$ emissions.

- Increasing compression ratio. Additional strategy to achieve complete combustion of pyrolysis oil is an increase of engine compression ratio to 22-24, which leads to higher in-cylinder temperatures at the end of compression stroke [30]. In addition, such high compression ratios cannot be realized with highly boosted engines, which yield high power densities and high effective efficiencies.

Generally, most of the studies with TPO were performed using stationary single cylinder Diesel engines [16,20-22,26,30]. Studies with multi-cylinder turbocharged engines $[15,23,24]$ were generally not performed with the pure TPO with the exception of study in [24], where pure TPO was utilized in turbocharged multi-cylinder engine without hardware modifications at high loads, where boost pressure and thus intake air temperature are sufficiently high. Literature review of possible methods to utilize pure TPO in Diesel engines is therefore revealing that all presented approaches have a common goal increasing temperature at SOI [24,29-31]. Although increasing the cetane number by 
blending TPO either with cetane improvers [21], Diesel fuel [15,16,20,22-25] or methyl esters $[26,27,10]$ is suitable, the objective of this study is to analyse the behaviour of pure TPO as this gives the biggest economical advantage in future utilization of TPO.

\subsection{Innovative approach to utilization of the TPO in Diesel engines}

Apart from methods presented above, increase in temperature at SOI of the main injection can also be achieved by tailoring the injection strategy of a Diesel engine. In case of the TPO, introduction of the pilot injection is a novel approach that allows for the use of the pure TPO in a turbocharged and intercooled engine without any hardware modifications. It is furthermore shown in the paper that additional benefits can be achieved by tailoring the injection timing of the pilot injection, which can be realized in a modern, common rail engine that is seldom analysed in the publically available studies on the TPO. A comparison of existing methods and the proposed method is presented in Fig. 1.

104

105

106

107

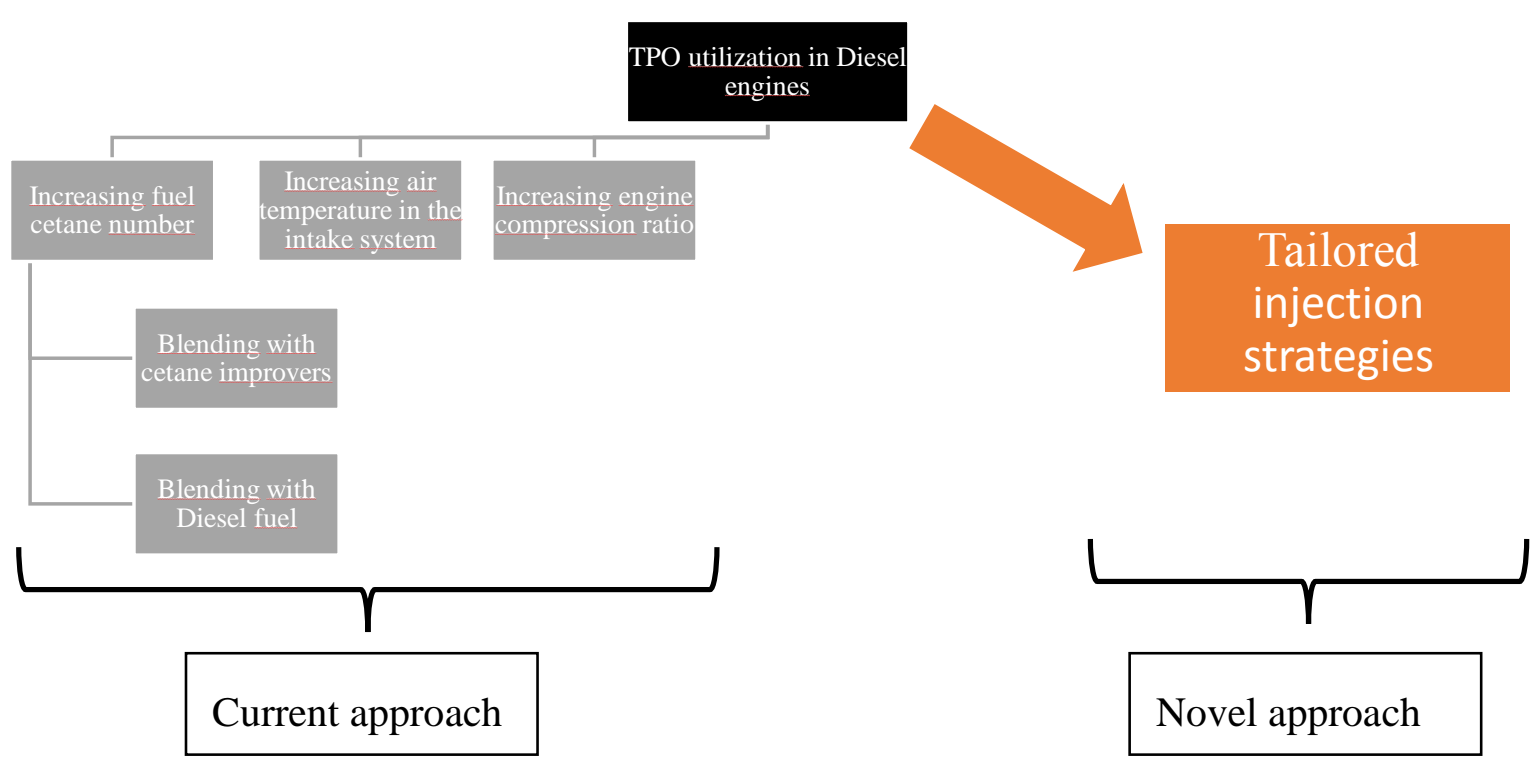

Fig. 1: A schematic diagram of the TPO utilization methods in internal combustion engines

Presented results thus indicate that a Diesel-like combustion of the TPO can be achieved in modern turbocharged and intercooled Diesel engines by tailoring injection strategies only. An additional goal of the presented study is also to extend the operating range of the turbocharged and intercooled Diesel engine in terms of load and speed variability by again utilizing tailored injection strategies only. This is demonstrated on the low-mid engine load and speed operating points. Successful Diesel-like combustion of the pure TPO that is realized by the advanced control strategies, without the need for hardware modifications or the use of cetane improvers or additional energy use for heating, thus significantly facilitates the use of the TPO and boosts its conversion efficiency to mechanical work. Furthermore, fundamental contributions on the interactions between the injection parameters and combustion as well as emission formation phenomena on the one hand establish the basis for reasoning the needs on adaptations published in the previous researches related to the use of the TPO, whereas, on the other hand, they open the way to use pure TPO in a very wide range of operating conditions of modern turbocharged and intercooled Diesel engines.

\subsection{TPO emission characteristics}

Utilization of TPO in Diesel engines affects along with combustion characteristics also emission response of the engine. Among the TPO studies, emission response of multi-cylinder 
four stroke Diesel engine with pure TPO is analysed in Ref. [24]. Authors reported that higher nitrogen content of the TPO increases $\mathrm{NO}_{\mathrm{x}}$ emission, compared with the D2 [24]. Furthermore, lower cetane number of TPO, compared to $\mathrm{D} 2$, results in additional increase of $\mathrm{NO}_{\mathrm{x}}$ emissions in low load operating points [24]. Higher CO and THC emissions of pure TPO, compared to D2, can be ascribed to shorter combustion durations and longer time needed for heavy TPO components to form combustible mixture, respectively [24]. Similar trend was reported for $\mathrm{NO}_{\mathrm{x}}$ emissions in the study [32], where TPO was blended at 5 vol.\% with D2 (5TPO) and tested in a four stroke automotive engine. Higher concentrations of $\mathrm{NO}_{\mathrm{x}}$ for 5TPO, compared to D2, before catalyst were ascribed to its higher nitrogen content as well as its higher aromatic content and lower $\mathrm{H} / \mathrm{C}$ ratio [32]. High aromatic content is also the cause of higher toluene $\left(\mathrm{C}_{7} \mathrm{H}_{8}\right)$ emissions of 5TPO, compared to D2 [32]. These reported trends in agreement with results reported in other publications. Murugan et al. [28] used four stroke single cylinder engine for analysing combustion and emission characteristics of blends up to $70 \mathrm{vol} \%$ TPO-Diesel mixtures . They ascribed increase of $\mathrm{NO}_{\mathrm{x}}$ emissions to higher aromatic content of TPO fuel, increase of $\mathrm{HC}$ emissions to higher viscosity, density and poor volatility of TPO and increase of $\mathrm{CO}$ emissions to poor mixture preparation, inefficient combustion due to higher viscosity and poor volatility, when the TPO share in the mixture was being increased [28]. Another set of experiment was conducted on a single cylinder, four stroke Diesel engine with various fuel blends of the TPO and the Diesel fuel and pure TPO [22]. TPO blends produced higher HC, $\mathrm{CO}$ and $\mathrm{SO}_{2}$ emissions due to poor atomization, lower cetane number and longer ignition delays of TPO, compared to D2, as explained by authors [22]. Study [33] reported results on engine performance and exhaust emissions in a four stroke naturally aspirated direct injection Diesel engine where the effect of tire-derived fuel in blends up to 90 vol.\% of TPO mixture with D2 was analysed. Authors determined that increased share of TPO results in decrease of CO and $\mathrm{HC}$ emissions at lower engine speeds and their increase at higher engine speeds [33]. Substantial increase of $\mathrm{NO}_{\mathrm{x}}$ is present at all engine speeds [33]. The emissions were explained with difference in density, volatility, viscosity and aromatic content between D2 and TPO [33].

\section{Fuel properties}

Composition of tire pyrolysis oil has been shown to consist of both short and long chain carbon molecules, single and multiple chain structures [34]. The TPO used in this study was produced by the vacuum pyrolysis method, which has the potential to produce a low sulphur fuel with reasonably high yield from tires [34]. Pyrolysis process was performed between $600^{\circ} \mathrm{C}$ and $700^{\circ} \mathrm{C}$ and the retention time of waste tires pieces (mean size $100 \mathrm{~mm} \times 100 \mathrm{~mm}$ ), of which steel wires and fabrics were previously removed, was $60 \mathrm{~min}$. TPO fuel, utilized in this study consists of fractions between $190^{\circ} \mathrm{C}$ and $350^{\circ} \mathrm{C}$.

The main properties of the TPO and D2 are presented in Table 1. Utilized D2 complies with the specifications of the SIST EN-590 [35] standard. Lower heating value (LHV) on mass basis is for TPO fuel lower than for D2, although it features higher density, which results in higher volumetric energy density for TPO fuel. In spite of reduced C and H content, TPO still features relatively high LHV due to higher sulphur content, compared to D2, which contributes to heating value and compensates the inert components in the fuel (namely $\mathrm{N}$ and $\mathrm{O}$ ). From the elemental composition, presented in Table 1 , slightly lower $\mathrm{H} / \mathrm{C}$ ratio for TPO compared to D2 can be calculated. The result is a consequence of its molecular composition with a higher number of double bonds and polycyclic aromatic hydrocarbons than D2 fuel.

TPO exhibits poor ignition properties, which is reflected in its relatively low cetane number. its low number indicates the fuel requires higher activation energy and thus higher auto-ignition 
173 temperature. It seems generally accepted that the cetane number of TPO is certainly below 30 174 [30,36], although in a study of 2015 authors achieved [16] that the blend of 25\% D2 fuel and

$17575 \%$ low sulphur tire fuel resembles in a cetane number of 51. Furthermore, they managed to 176 produce TPO fuel with a cetane number of 44 before entering the desulfurization process [37]. 177 Conventional D2 has a cetane number of at least 51, as set in the European standard SIST EN 178590 [35]. The difference between D2 and TPO cetane numbers was in this study estimated by 179 the calculated value of cetane index (CI) (Table 1). Although the transferability of CI among 180 fuels with significantly different molecular composition is questionable [38], it is, based on the 181 observations from several researchers in aforementioned studies dealing with TPO, at least 182 partly appropriate as it always suggests lower CI than for D2, which is also confirmed through 183 combustion behaviour in Diesel engines. 


\begin{tabular}{|c|c|c|}
\hline Property\Fuel & TPO & D2 \\
\hline Density [kg/L] [39] & $0.92 \pm 0.0003$ & $0.83 \pm 0.0003$ \\
\hline LHV on mass basis $[\mathrm{MJ} / \mathrm{kg}][40]$ & $42.7 \pm 0.07$ & $42.95 \pm 0.07$ \\
\hline LHV on volume basis $[\mathrm{MJ} / \mathrm{L}]$ & $39.3 \pm 0.07$ & $35.6 \pm 0.07$ \\
\hline Water content [mg/kg] [41] & $118 \pm 20$ & $<30 \pm 20$ \\
\hline Stoichiometric ratio & $\sim 13.8$ & 14.7 \\
\hline $\begin{array}{l}\text { Energy content of the stoichiometric mixture } \\
{[\mathrm{MJ} / \mathrm{kg}]}\end{array}$ & $\sim 2.89$ & 2.74 \\
\hline Aromatic content $[\% \mathrm{~m} / \mathrm{m}][42]$ & $39.3 \pm 0.8$ & $26.0[43]$ \\
\hline Viscosity $\left[\mathrm{mm}^{2} / \mathrm{s}\right]$ & $3.22 @ 20^{\circ} \mathrm{C}$ & $2.54 @ 40^{\circ} \mathrm{C}$ \\
\hline $\mathrm{C}[\% \mathrm{~m} / \mathrm{m}]$ & $83.45-85.60[17]$ & 87.0 \\
\hline $\mathrm{H}[\% \mathrm{~m} / \mathrm{m}]$ & $9.59-11.73[17]$ & 13.0 \\
\hline $\mathrm{N}[\% \mathrm{~m} / \mathrm{m}]$ & $0.40-1.05[17]$ & / \\
\hline $\mathrm{S}[\% \mathrm{~m} / \mathrm{m}]$ & 0.96 & $<0.001[35]$ \\
\hline $\mathrm{O}[\% \mathrm{~m} / \mathrm{m}]$ & $0.10-3.96$ & l \\
\hline $\mathrm{H} / \mathrm{C}$ ratio [ / ] & $0.112-0.140$ & 0.149 \\
\hline Distillation recovered at $250^{\circ} \mathrm{C}[\% \mathrm{~V} / \mathrm{V}]$ [44] & $54.1 \pm 2.4$ & $43.0 \pm 2.4$ \\
\hline Distillation recovered at $350^{\circ} \mathrm{C}[\% \mathrm{~V} / \mathrm{V}]$ [44] & $84.3 \pm 2.4$ & $97.0 \pm 2.4$ \\
\hline $95 \%(\mathrm{~V} / \mathrm{V})$ recovered at $\left[{ }^{\circ} \mathrm{C}\right][44]$ & $367.1 \pm 4.0$ & $343.0 \pm 4.0$ \\
\hline Calculated cetane index [45] & $28.6 \pm 1.5$ & $53.2 \pm 1.5$ \\
\hline Ash $[\% \mathrm{~m} / \mathrm{m}]$ & $>0.18$ & $<0.01[35]$ \\
\hline Cold filter plugging point $\left[{ }^{\circ} \mathrm{C}\right][46]$ & $20 \pm 2$ & $0 \pm 2$ \\
\hline
\end{tabular}

\section{Experimental}

\subsection{Engine setup}

188 The basis of the test set-up is a 4-cylinder, 4-stroke, turbocharged, intercooled 1.6 litre PSA 189 light-duty Diesel engine (model DV6A TED4), which was coupled with a Zöllner B-350AC 190 eddy-current dynamometer controlled by Kristel, Seibt \& Co. control system KS ADAC. The 191 main characteristics of the engine are given in Table 2 and the general scheme of the 192 experimental system is presented in Fig. 2.

193 Table 2: Engine specifications

\begin{tabular}{ll}
\hline Engine & PSA DV6ATED4 \\
\hline Cylinders & 4, inline \\
Engine type & 4 -stroke \\
Displacement & $1560 \mathrm{~cm} 3$ \\
Bore $\times$ stroke & $75 \mathrm{~mm} \times 88.3 \mathrm{~mm}$ \\
Compression ratio & $18: 1$ \\
Fuel injection system & Common rail, up to 1600 bar \\
Maximum power & $66 \mathrm{~kW} @ 4000 \mathrm{rpm}$ \\
Maximum torque & $215 \mathrm{Nm} @ 1750 \mathrm{rpm}$ \\
Gas path & Turbocharger, intercooler
\end{tabular}




\begin{tabular}{ll} 
EGR valve & closed \\
Wastegate & closed \\
Cooling system & Water cooled \\
Valve train & DOHC, $16 \mathrm{~V}$ \\
Con. Rod & $136.8 \pm 0.075 \mathrm{~mm}$ \\
Piston pin offset & $0.4 \pm 0.075 \mathrm{~mm}$ \\
\hline
\end{tabular}

A Kistler CAM UNIT Type 2613B shaft encoder provided an external trigger and an external clock at $0.1{ }^{\circ} \mathrm{CA}$ for data acquisition and injection control system. In-cylinder pressure was measured with calibrated piezo-electric pressure transducer AVL GH12D, mounted into a third cylinder, in combination with charge amplifier AVL MICROIFEM, connected to 16 bit, 4 channel National Instruments data-acquisition system with maximum sampling frequency 1 $\mathrm{MS} / \mathrm{s} / \mathrm{ch}$. The maximum uncertainty of pressure measurement is $0.31 \%$ [47], which combines uncertainties of pressure transducer, charge amplifier and analog voltage input measurement card. Top dead centre was determined by capacitive sensor COM Type 2653 with maximum uncertainty of less than $0.05^{\circ} \mathrm{CA}$ while considering also speed change of the engine.

The data acquisition and injection control embedded system, in Fig. 2 depicted as NI cRIO system, was based on National Instruments cRIO 9024 processing unit and 9114 chassis. Along with indication of pressure traces, it generated digital output signals to set start and duration of injectors energizing at Drivven system, which can be set in PC graphic user interface. Drivven system generated inlet metering valve signal (IMV signal) and injector energizing signal (IE signal) to control common rail pressure and fuel injection times. It was connected to the PC, and the energizing characteristic for the injectors along with other Drivven parameters was set by CalView software.

Two fuel tanks with separate fuel filters were used in the fuel supply system: one for the standard D2 and another for the TPO fuel. An AVL 730 gravimetric balance with the general measuring accuracy of $\pm 0.12 \%$ was employed to measure fuel consumption. Intake air flow was measured with Meriam laminar flow meter 50MC2-6F. Additionally, the engine was fitted with instrumentation for measurement and monitoring temperature and pressure (intake air, exhaust gases, lubrication oil, coolant etc.).

The exhaust emissions were analysed and recorded using a portable exhaust monitoring equipment Horiba OBS-2200, which provides accuracy of $\pm 2.5 \%$ of full scale. A heated sampling pipe with a temperature of $195^{\circ} \mathrm{C}$ was used to guide wet exhaust gases from sampling attachment on the exhaust pipe to the measuring device. Horiba emission measurement devices comprise of non-dispersive infrared analyser (NDIR) for detection of carbon monoxide (CO) and carbon dioxide $\left(\mathrm{CO}_{2}\right)$, flame ionization detector (FID) for detection of total hydrocarbons (THC) and chemiluminescent detector (CLD) for detection of $\mathrm{NO}_{\mathrm{x}}$ emissions. 


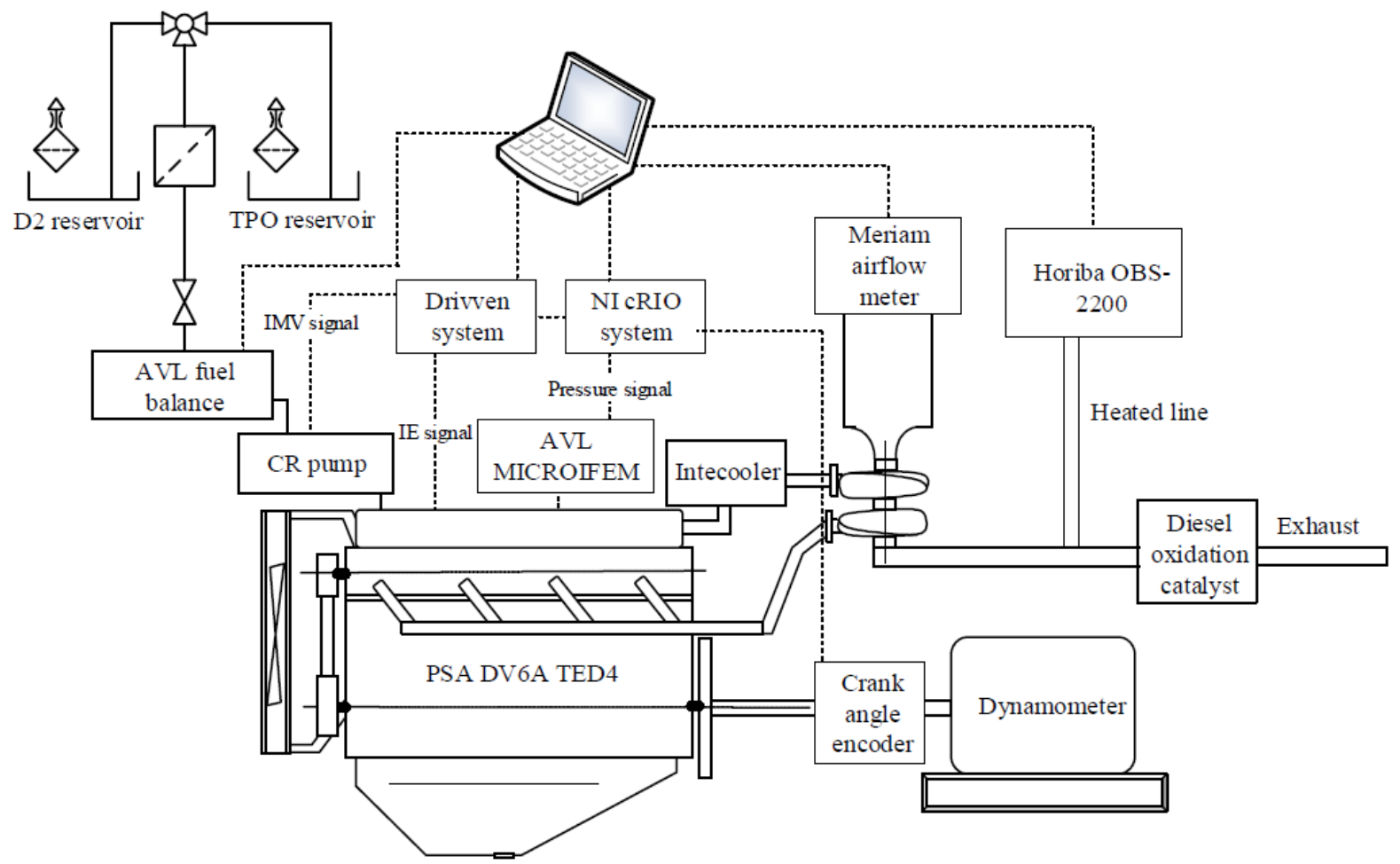

Fig. 2: A schematic diagram of the experimental setup

\subsection{Test procedure}

Experiments were performed in thermally stabilized steady-state engine operating points at different engine loads. All experiments were conducted by starting engine with a D2 and afterwards a transition to TPO was performed for entering the part of the experiments matrix related to the TPO, as it is not possible to start the engine with pure TPO due to its low cetane number. Before starting the TPO experiments and following the transition from the D2, the engine was run with TPO for one hour at mid-load to ensure efficient purging of the fuel injection system. In baseline experiments, injection parameters and injection pressure were equal to those in the original ECU injection strategy for warmed up engine and ambient conditions of standard atmosphere. These parameters were then subject to modifications as presented in this section. Modification of injection parameters were performed on all four cylinders with the exception of the cases, which do not feature a pilot injection (denoted by "No Pilot injection" or NP). In these cases, pilot injection was omitted only in the cylinder that was indicated. This was done to avoid engine stops in the cases of unstable combustion with the TPO as analysed in the next section. Besides thermodynamic parameters, exhaust emissions were also measured to provide additional insight into combustion phenomena of the TPO.

\subsubsection{Thermodynamic analysis}

To systematically analyse different impacts of injection strategy and to establish a continuity with previous works, e.g. [24], impact of introducing a pilot injection on combustion characteristics was analysed first. This analysis was performed at engine speed $1500 \mathrm{rpm}$ and two different load points. Results of previous study [24] indicate that operation with pure TPO in turbocharged non-intercooled Diesel engine was feasible only at high loads. Therefore, lowto mid-loads were investigated in this analysis. Table 3 lists cases for operating points at 1500 rpm, among which cases D2_158 and D2_1514 (the first part of the name corresponds to fuel and the second part to engine speed and load as given in Table 3) were indicated while ECU injection strategy was utilized. In order to maintain the same brake mean effective pressure (BMEP) values for D2 and TPO fuel cases, the main injection duration was adapted for the 
TPO cases TPO_158 and TPO_1514, while SOI values were the same as for D2. Furthermore, in cases D2_NP_158, D2_NP_1514, TPO_NP_158 and TPO_NP_1514 (NP denotes "No Pilot injection"), the injection timing of the main injection was retained while omitting the pilot injection just in the indicated cylinder. Therefore BMEP, calculated from engine torque, is not representative for the cases without pilot injection and will not be presented in the Table 3 for those cases. Additionally, coefficient of variation of the in-cylinder peak pressure, expressed as the ratio between the standard deviation $(\sigma)$ and the mean value of the maximum pressure averaged over hundred cycles was calculated and presented in the Tables 3 and 4. Lower COV values for the D2 compared to the one of the TPO fuel indicate that combustion process of the $\mathrm{D} 2$ is more stable and repeatable than the one of the TPO fuel.

Table 3: Indicated cases with ECU injection strategy and without pilot injection

\begin{tabular}{lllll}
\hline Operating point & $\mathrm{D} 2 \_158$ & $\mathrm{D} 2 \_\mathrm{NP} \_158$ & $\mathrm{D} 2 \_1514$ & $\mathrm{D} 2 \_\mathrm{NP} \_1514$ \\
\hline Fuel & $\mathrm{D} 2$ & $\mathrm{D} 2$ & $\mathrm{D} 2$ & $\mathrm{D} 2$ \\
Rail pressure [bar] & 850 & 850 & 900 & 900 \\
Speed [rpm] & 1500 & 1500 & 1500 & 1500 \\
Torque [Nm] & 79 & 77 & 141 & 139 \\
IMEP [bar] & 6.9 & 6.1 & 11.1 & 10.3 \\
Indicated fuel conversion & & & & \\
efficiency [\%] & 39.2 & 38.9 & 37.3 & 37.9 \\
Air mass flow [kg/s] & $2.31 \times 10^{-2}$ & $2.30 \times 10^{-2}$ & $2.68 \times 10^{-2}$ & $2.67 \times 10^{-2}$ \\
Fuel mass flow [kg/s] & $7.95 \times 10^{-4}$ & $7.72 \times 10^{-4}$ & $1.35 \times 10^{-3}$ & $1.32 \times 10^{-3}$ \\
Start of pilot injection [ $\left.{ }^{\circ} \mathrm{CA}\right]$ & -30 & $/$ & -31 & $/$ \\
Start of main injection [ $\left.{ }^{\circ} \mathrm{CA}\right]$ & 0 & 0 & -2 & -2 \\
Max. Pressure COV [\%] & 0.45 & 0.68 & 0.47 & 0.42 \\
\hline Operating point & $\mathrm{TPO} 158$ & $\mathrm{TPO} \mathrm{NP}_{-} 158$ & $\mathrm{TPO} 1514$ & $\mathrm{TPO} \mathrm{NP}_{-} 1514$ \\
\hline Fuel & $\mathrm{TPO}$ & $\mathrm{TPO}$ & $\mathrm{TPO}$ & $\mathrm{TPO}$ \\
Rail pressure [bar] & 850 & 850 & 900 & 900 \\
Speed [rpm] & 1500 & 1501 & 1500 & 1500 \\
Torque [Nm] & 79 & 71 & 144 & 144 \\
IMEP [bar] & 7.3 & $/$ & 11.1 & 9.6 \\
Indicated fuel conversion & & & & \\
efficiency [\%] & 38.3 & $/$ & 35.2 & 33.5 \\
Air mass flow [kg/s] & $2.34 \times 10^{-2}$ & $2.34 \times 10^{-2}$ & $2.71 \times 10^{-2}$ & $2.70 \times 10^{-2}$ \\
Fuel mass flow [kg/s] & $8.70 \times 10^{-4}$ & $8.54 \times 10^{-4}$ & $1.44 \times 10^{-3}$ & $1.51 \times 10^{-3}$ \\
Start of pilot injection [ $\left.{ }^{\circ} \mathrm{CA}\right]$ & -30 & $/$ & -31 & $/$ \\
Start of main injection [ $\left.{ }^{\circ} \mathrm{CA}\right]$ & 0 & 0 & -2 & -2 \\
Max. Pressure COV [\%] & 1.4 & 0.14 & 0.46 & 4.8 \\
\hline
\end{tabular}

The second set of experiments consisted of two steady-state operating points at $1500 \mathrm{rpm}$ with the goal of investigating the SOI shift of pilot and main injections on combustion propagation and emissions of the TPO. Goal of this analysis was to approach Diesel-like combustion while utilizing the TPO to approach similar thermal and mechanical stresses of the engine. Analysed cases are presented in the Table 4, where positive shift values represent retarded SOI. On the basis of the preliminary in-cylinder pressure analysis, two different pilot injection shift values were chosen. 
Table 4: Indicated cases with pilot injection and main injection shifting with relation to ECU 272 injection strategy

\begin{tabular}{lll}
\hline Operating point & TPO_SH_5_158 & TPO_SH_9_1514 \\
\hline Fuel & TPO & TPO \\
Rail pressure [bar] & 850 & 900 \\
Speed [rpm] & 1501 & 1500 \\
Torque [Nm] & 80 & 144 \\
IMEP [bar] & 6.8 & 11.3 \\
Indicated fuel conversion efficiency [\%] & 38.5 & 35.4 \\
Air mass flow [kg/s] & $2.34 \times 10^{-2}$ & $2.72 \times 10^{-2}$ \\
Fuel mass flow [kg/s] & $8.06 \times 10^{-4}$ & $1.45 \times 10^{-3}$ \\
Pilot injection shift relative to original & 5 & 9 \\
[ ${ }^{\circ} \mathrm{CA}$ ] & 5.57 & 1.7 \\
Max. Pressure COV [\%] & 0.57
\end{tabular}

Thermodynamic parameters and emissions were measured continuously while in-cylinder pressure was indicated over 100 consecutive cycles as proposed in [12]_at a sampling resolution of $0.1^{\circ} \mathrm{CA}$. To eliminate noise, averaging of cycles was performed. In addition, it is advantageous to eliminate cycles featuring large cyclic variability from the averaged cycle. In the literature, different averaging techniques that comprise from 25 [48] up to 500 [49] engine cycles. In our case, 100 cycles were used to determine the averaged pressure trace, with the exception of the point TPO_NP_1514, where only a single cycle was analysed due to large cycle-to-cycle variations caused by instable combustion. Additionally, averaged pressure trace was filtered with low-pass finite impulse response (FIR) filter, as proposed in [48], in order to remove high frequency components of the pressure trace before being used in calculation of thermodynamic parameters that include pressure derivative.

Thermodynamic parameters, including rate of heat release (ROHR), rate of pressure rise and in-cylinder temperature were calculated with AVL Burn software [50]. Employed software tool is based on detailed OD thermodynamic equations considering variable gas properties determined via the NASA polynomials and relevant partial derivatives of non-perfect gases as well as the compressibility factor. Detailed equations for zero dimensional ROHR calculation, which are based on mass, enthalpy and species conservation, are presented in [51]. The heat losses from the combustion chamber to the cylinder walls were calculated using Hohenberg heat transfer model [52].

\subsubsection{Emission analysis}

Emission analyses were performed for basic exhaust gas species - THC, CO and $\mathrm{NO}_{\mathrm{x}}$. Emissions of $\mathrm{CO}_{2}$ and $\mathrm{H}_{2} \mathrm{O}$ will not be discussed here, as they directly correlate to fuel consumption and carbon balance. The similar trend was proven also for $\mathrm{SO}_{2}$, which is almost linearly dependent on the cyclic energy delivery [24] as presented in the Appendix, so $\mathrm{SO}_{2}$ emissions will not be discussed here. However, it has to be noted that when fuels with high sulphur content are used, appropriate exhaust after treatment technologies are required (i.e. wet scrubbing) and engine design should be adapted to high sulphur content in exhaust gasses to avoid problems with corrosion due to $\mathrm{H}_{2} \mathrm{SO}_{4}$ formation.

Emissions were measured in all operating points presented in Table 3 and Table 4. The only exception were emission measurements in the operating points with seriously impaired combustion process, i.e. in the operating points with unstable or no combustion, where exhaust gas analysis was not performed in order to protect the emission equipment due to expected concentrations outside of the measuring range. 


\section{Results and discussion}

\subsection{Combustion parameters}

In this section, the thermodynamic parameters and emissions for all cases, listed in Tables 3 and 4 are presented. Performances of TPO and D2 are compared in order to analyse the interrelation between injection strategies and combustion characteristics of the TPO fuel in the modern turbocharged and intercooled Diesel engines. In the Fig. 3 in-cylinder pressure traces ( $3 \mathrm{a}$ and $3 \mathrm{f}$ ), ROHR ( $3 \mathrm{~b}$ and $3 \mathrm{~g}$ ), rate of pressure rise ( $3 \mathrm{c}$ and $3 \mathrm{~h}$ ), in-cylinder temperature traces ( $3 \mathrm{~d}$ and $3 \mathrm{i}$ ) and injector energizing times ( $3 \mathrm{e}$ and $3 \mathrm{j}$ ) depending on crank angle are presented. In both operating points, a comparison will be made between D2 and TPO parameters.

\subsubsection{Operating points without pilot injection}

First, operating points without the pilot injection will be analysed as this establishes a link to previous studies listed in the introduction that were to the best of authors' knowledge all performed without the pilot injection. In Fig. 3 operating points without the pilot injection are denoted by "D2_NP" and "TPO_NP",

It is discernible from Fig. 3 that, at $1500 \mathrm{rpm}$ and $80 \mathrm{Nm}$ (this corresponds to slightly more than $35 \%$ of the maximum torque), no combustion is present when using the TPO. Only slightly negative ROHR values that are related to fuel evaporation can be observed after fuel injection. This result is fully in line with the conclusions drawn in [12], where stable combustion with pure TPO was achieved only at high loads and in a turbocharged engine without the intercooler as sufficiently high temperature was required at SOI. This result is also in line with the results of other studies that increasing temperature at SOI, increasing a cetane number of the TPO either with cetane improvers or blending with D2 is required to establish a stable combustion with the TPO.

Unlike for the TPO, stable and efficient combustion can be achieved without pilot injection when using D2 fuel at $1500 \mathrm{rpm}$ and $80 \mathrm{Nm}$, which is mainly due to its higher cetane number and thus lower activation energy. However, due to the lack of pilot injection and thus longer ignition delay period, combustion of D2 is also characterized by intense premixed combustion. This results in a higher rate of pressure rise, which exceeds threshold of $5.5 \mathrm{bar} /{ }^{\circ} \mathrm{CA}$ that is often set as the upper limit $[29,30]$.

Fig. 3 - right indicates that at $1500 \mathrm{rpm}$ and $140 \mathrm{Nm}$ (this corresponds to slightly more than $65 \%$ of maximum torque) TPO ignites despite the absence of the pilot injection. This can mainly be attributed to slightly higher temperatures around the TDC. At this point, it should be noted that the use of TPO was subjected to extremely irregular combustion and cycle-to-cycle variability in this operating point was very high. Therefore, cycle averaging could not be performed and thus the thermodynamic parameters, depicted with the curve "TPO_NP", are calculated on the basis of a filtered pressure curve of a single cycle, where the mixture was successfully ignited (there were also non-firing cycles present). Despite selecting the cycle where TPO was successfully ignited, it can be observed that operation with TPO without pilot injection is characterized by an extremely prolonged ignition delay period, followed by a very intense premixed combustion period that results in a very high rate of pressure rise values of more than $13 \mathrm{bar} /{ }^{\circ} \mathrm{CA}$. This result is also in line with the results presented in [12] and clearly indicates that it is not feasible to operate turbocharged and intercooled Diesel engines with pure TPO also at higher loads with only single main injection.

It can again be observed that stable combustion can be achieved without pilot injection when using D2 fuel at $1500 \mathrm{rpm}$ and $140 \mathrm{Nm}$. Due to higher load yielding higher injection pressure and larger injected fuel mass, which promotes mixture formation, the premixed part of the 
combustion is not as pronounced for the D2 case without pilot injection. Therefore, the shape of the ROHR trace of the D2 without pilot injection (D2_NP) deviates less from the D2 case with pilot injection (D2) in this operating point in comparison to TPO. For this reason, this operating point is also characterized by lower values of rate of pressure rise.

\subsubsection{Operating points with pilot injection}

The baseline case analysed in this study (D2) features the same injection parameters and injection pressure as the original ECU injection strategy, whereas the case "TPO" features adapted duration of the main injection to meet the same BMEP values, featured in D2 cases.

In Fig. 3 at $1500 \mathrm{rpm}$ and $80 \mathrm{Nm}$ it can be seen that introduction of pilot injection represents a key modification that allows successful utilization of the TPO in turbocharged and intercooled Diesel engines even at low loads. When timing of injection parameters was unaltered (case TPO), the premixed combustion of TPO resembles the one of the D2 fuel without pilot injection (D2_NP) featuring also similar rates of pressure rise that can be considered at an upper acceptable limit $\left(5.5 \mathrm{bar} /{ }^{\circ} \mathrm{CA}\right)$ in terms of long-term engine operation. The ROHR curve indicates successful ignition of pilot injection that allows for successful ignition of the main injection. Comparing cases TPO and D2, both with pilot injection, it can be concluded that TPO features about $10^{\circ} \mathrm{CA}$ longer ignition delay period of the pilot injection than $\mathrm{D} 2$, which is mainly the consequence of a lower cetane number of the TPO. As a result, the TPO case features lower in-cylinder temperature at SOI of the main injection, which, in combination with its lower cetane number, results in a longer ignition delay period of the main injection yielding more intense premixed combustion and thus higher values of the rate of pressure rise compared to the D2 case.

Similar trends can also be observed at $1500 \mathrm{rpm}$ and $140 \mathrm{Nm}$. In the TPO case, there is again a longer ignition delay period of the pilot injection of approx. $10^{\circ} \mathrm{CA}$, compared to the $\mathrm{D} 2$ case. This also results in more pronounced premixed combustion peak, which is at this operating point less exposed at first sight than it is followed by more intense diffusion contribution to the ROHR, which is similar for the TPO and the D2 case.

\subsubsection{Shifted TPO injection}

It was presented in the previous section that introduction of the pilot injection is a pre-requisite to successful utilization of the TPO in turbocharged and intercooled Diesel engines. However, it was also shown that, when applying the same injection strategy as for the D2, TPO features more intense premixed combustion and thus higher rates of pressure rise. This section therefore analyses the potential of the shift of the pilot injection (Table 4) to reduce intensity of the premixed combustion of the TPO with the goal to achieve more Diesel-like combustion of the TPO injected in the main injection.

Fig. 3 indicates that shifting pilot injection of the TPO from $-30^{\circ} \mathrm{CA}$ to $-25^{\circ} \mathrm{CA}$ in the operating point 1500 rpm and $80 \mathrm{Nm}$ (TPO_SH_5) results in a similar ignition delay as in the case without the injection shift (TPO), thus yielding later combustion of the fuel injected in the pilot injection. However, as the pilot injection was injected later in the compression phase, the incylinder charge features higher pressure and thus density resulting in lower spray liquid length [55] and wider spray-spreading angles [56]. ROHR trace for the case TPO_SH_5 thus indicates that injection of the main TPO quantity in this larger volume of burning TPO which was injected during pilot injection reduces the ignition delay period of the main injection and thus results in less intense premixed combustion as well as Diesel-like combustion of the TPO injected in the main injection. Shift of pilot injection therefore also reduces the value of the rate of pressure rise for the TPO_SH_5 under $4 \mathrm{bar} /{ }^{\circ} \mathrm{CA}$. 
398 The same procedure of shifting the pilot injection was also applied to the operating point at $3991500 \mathrm{rpm}$ and $140 \mathrm{Nm}$, where pilot injection was retarded from $-31^{\circ} \mathrm{CA}$ to $-22^{\circ} \mathrm{CA}$, denoted as 400 "TPO_SH_9". Unlike in the operating point $1500 \mathrm{rpm}$ and $80 \mathrm{Nm}$, it can be observed that at $4011500 \mathrm{rpm}$ and $140 \mathrm{Nm}$, the shift in pilot injection resulted in more intense ROHR during the 402 early phase of the combustion of the TPO injected during the pilot injection. This can again be 403 attributed to wider spray spreading angle, which causes more intense mixing of the fuel with 404 the in-cylinder charge and thus more intense heating of the TPO, which at this operating point 405 results in reduced ignition delay followed by a more intense ROHR of the TPO injected during 406 the pilot injection. Consequently, reduced intensity of the premixed combustion of the TPO 407 injected in the main injection and thus its more Diesel-like combustion can also be observed 408 for the operating point $1500 \mathrm{rpm}$ and $140 \mathrm{Nm}$. 
$1500 \mathrm{rpm}, 80 \mathrm{Nm}$

a.)

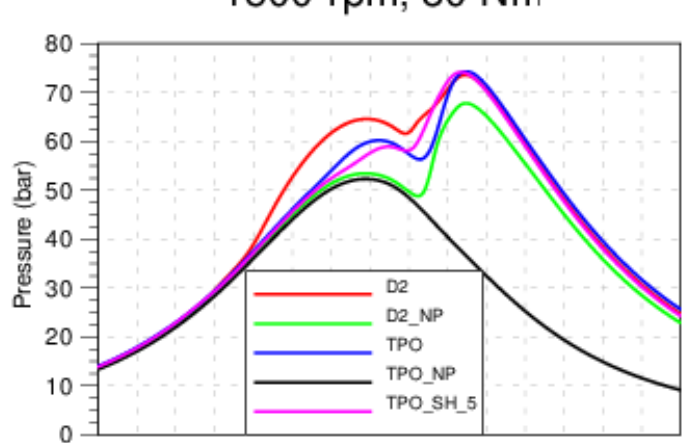

b.)

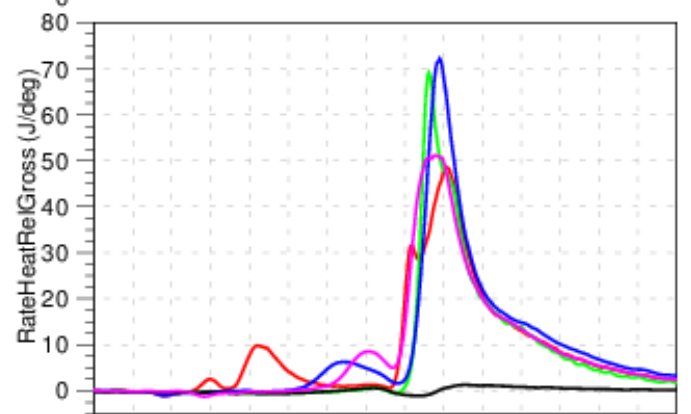

c.)

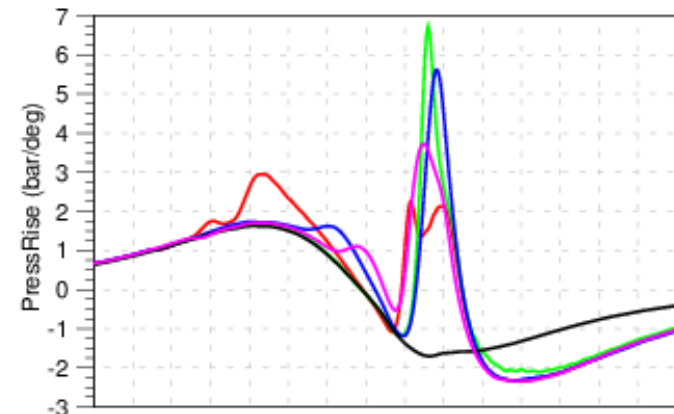

d.)

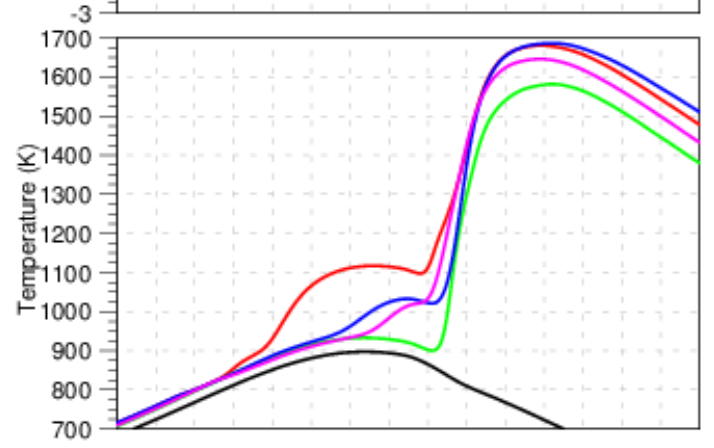

e.)

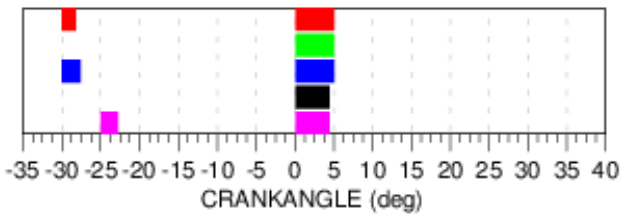

$1500 \mathrm{rpm}, 140 \mathrm{Nm}$

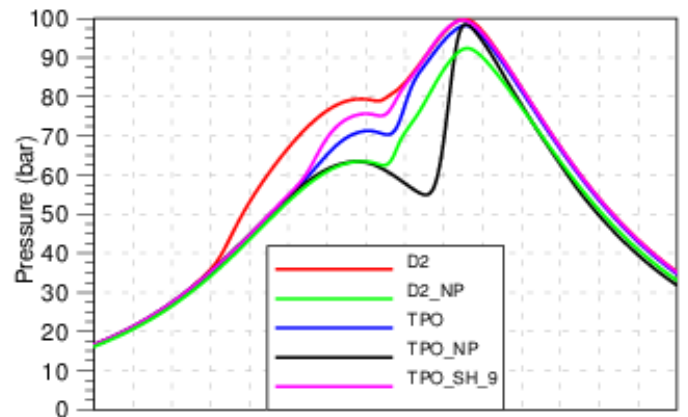

f.)

g.)
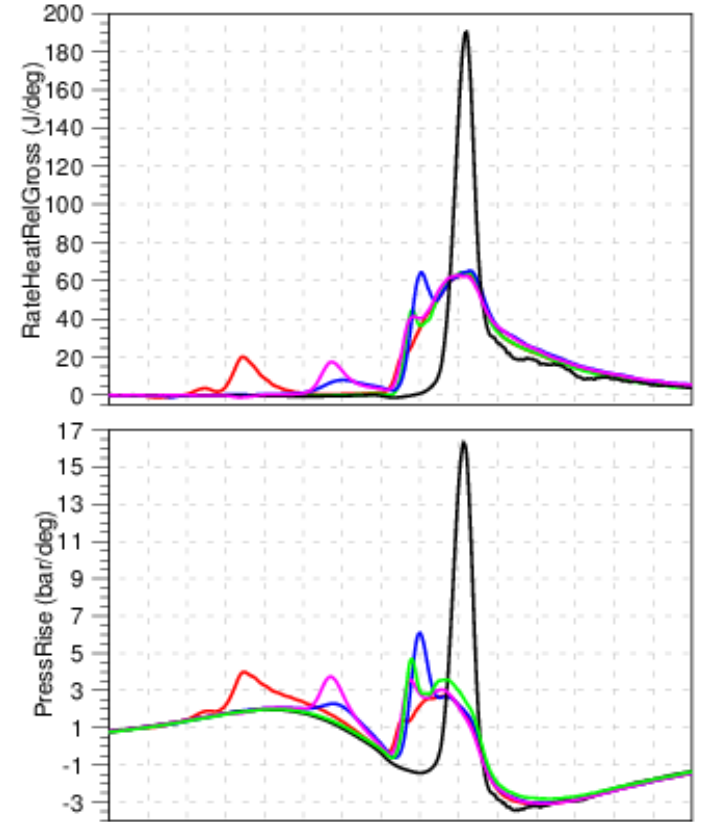

h.)

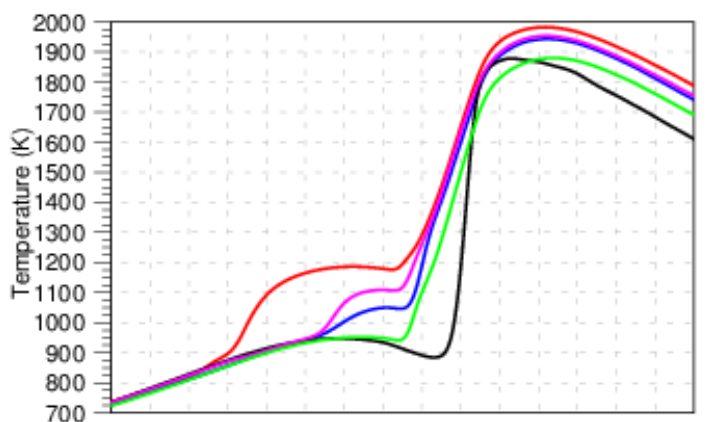

i.)

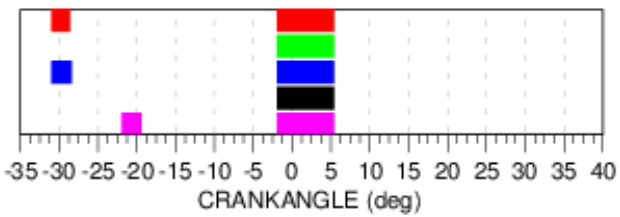

j.)

Fig. 3: a.) Pressure trace, b.) ROHR, c.) Rate of pressure rise, d.) Temperature and e.) Injector 412 energizing timings for operating point at $1500 \mathrm{rpm}$ and $80 \mathrm{Nm}$; f.) Pressure trace, g.) ROHR, 413 h.) Rate of pressure rise i.) Temperature and $j$.) Injector energizing timings for operating point 414 at 1500 rpm and $140 \mathrm{Nm}$; 
416 In this section, the emission response of the analysed operating points (Table 3 and Table 4) is 417 presented. As indicated in section 3.2.2, emissions were not measured in operating points with 418 unstable or no combustion, i.e. TPO_NP_158 and TPO_NP_1514, and thus these results are not presented in this section. The main reason for this is protection of measuring hardware. A seriously impaired combustion process was already identified from in-cylinder pressure analysis in the above section and emissions surpassing analyser measuring range were expected as described in Section 3.2.2.

The following sections present results with the original ECU injection strategy, i.e. with pilot injection, where remarkably similar emission response to D2 is demonstrated in medium-load point and results in shifted pilot injection timing. The results are grouped in Fig. 4, where:

- D2 is denoting D2 with ECU injection strategy,

- TPO is denoting tire pyrolysis oil with ECU injection strategy,

TPO_SH is denoting tire pyrolysis oil with shifted injection strategy as described in Table 3 and Table 4 (numbers related to the shift angles are not added in this section to preserve clarity of notations in the figures, whereas they are identical to those specified in Tables 3 and 4)

\subsubsection{Low-load operation - $1500 \mathrm{rpm}$ and $80 \mathrm{Nm}$}

\section{THC emissions}

At $1500 \mathrm{rpm}$ and $80 \mathrm{Nm}$, the THC emissions of TPO with pilot injection and original injection timing (Fig. 4b) are slightly above those of D2, which is in line with several studies, found in the literature $[24,28,37]$. This can be mainly attributed to two facts. First, the TPO is composed of a higher share of ignition-resistant hydrocarbons [57]. Second and more important, at 1500 rpm and $80 \mathrm{Nm}$, the TPO is characterized by longer ignition delay of pilot injection (Fig. 3). During this period, the TPO is subjected to a higher rate of premixing, which can influence the THC emissions through two mechanisms:

- Prolonging the premixing process due to ignition delay results in increasing the air-fuel ratio of the premixed mixture, which could increase the volume of the mixture outside the flammability limits at the lean end.

- Migration of the mixture into colder parts of the combustion chamber (i.e. near wall regions, crevices). This prevents ignition and leads to local flame extinctions, which is more pronounced for the TPO due to its low cetane number of TPO [36].

At $1500 \mathrm{rpm}$ and $80 \mathrm{Nm}$, the THC emissions of the case with shifted pilot injection of the TPO (TPO_SH) from $-30^{\circ} \mathrm{CA}$ to $-25^{\circ} \mathrm{CA}$ slightly increase above those of TPO with original injection timing. This is due to a later pilot injection, where higher density and temperature of the cylinder charge reduces spray liquid length [55], whereas higher density also contributes to larger sprayspreading angle [56], which leads to a more dispersed spray. This can effectively increase the air-fuel ratio of premixed mixture and result in larger volumes of the mixture which is outside of flammability limits or compressed into crevices and near-wall regions where ignition is difficult and unreacted or partially reacted hydrocarbons are retained.

\section{CO emissions}

For $1500 \mathrm{rpm}$ and $80 \mathrm{Nm}$, the trends of CO emissions for TPO and TPO_SH (Fig. 4a) are very similar to THC emissions of TPO and TPO_SH, which was observed also in studies, where pure TPO [24] and its blends with Diesel fuel were utilized [28]. This can in general be attributed to the similar physical phenomena leading to $\mathrm{CO}$ formation as analysed for the THC 
emissions, although the formation of $\mathrm{CO}$ occurs slightly later, when partially reacted hydrocarbons further oxidize to $\mathrm{CO}$. The main difference here is that giving the sufficient amount of oxygen available, THC emissions originate from air-fuel mixture which is outside of flammability limits, whereas $\mathrm{CO}$ emissions originate from close vicinity of this areas, where already reacting mixture is diluted and cooled. This freezes the combustion reactions, leading to local lean flameouts and leaves partially oxidized carbon as a trace.

$N O_{x}$ emissions

The combustion of the TPO at $1500 \mathrm{rpm}$ and $80 \mathrm{Nm}$ is also characterized by higher $\mathrm{NO}_{\mathrm{x}}$ emissions (Fig. 4c) than D2. This can be attributed to a notable amount of fuel-bound nitrogen (FBN) in TPO (Table 1) which is mirrored in higher $\mathrm{NO}_{\mathrm{x}}$ emissions due to efficient conversion of FBN into $\mathrm{NO}_{\mathrm{x}}$. Similar results and explanation were published in various studies $[24,28,32,33]$. Additionally, the in-cylinder temperature plays an important role as it directly influences the thermal component of $\mathrm{NO}_{\mathrm{x}}$ formation. In case of TPO with original injection timing, the effect of temperature might promote reduction of the thermal $\mathrm{NO}_{\mathrm{x}}$, as temperatures are lower than for $\mathrm{D} 2$ in the phase of pilot combustion. However, this effect is obscured by high share of FBN component of $\mathrm{NO}_{\mathrm{x}}$. TPO_SH with shifted pilot injection exhibits even lower $\mathrm{NO}_{\mathrm{x}}$ emissions than TPO with original injection timing. This is again a consequence of lower temperature levels, not only in the pilot combustion phase but also in the phase of main combustion, as visible in Fig. 3 d, thus further reducing thermal $\mathrm{NO}_{\mathrm{x}}$ component in comparison to TPO_SH.

a.)

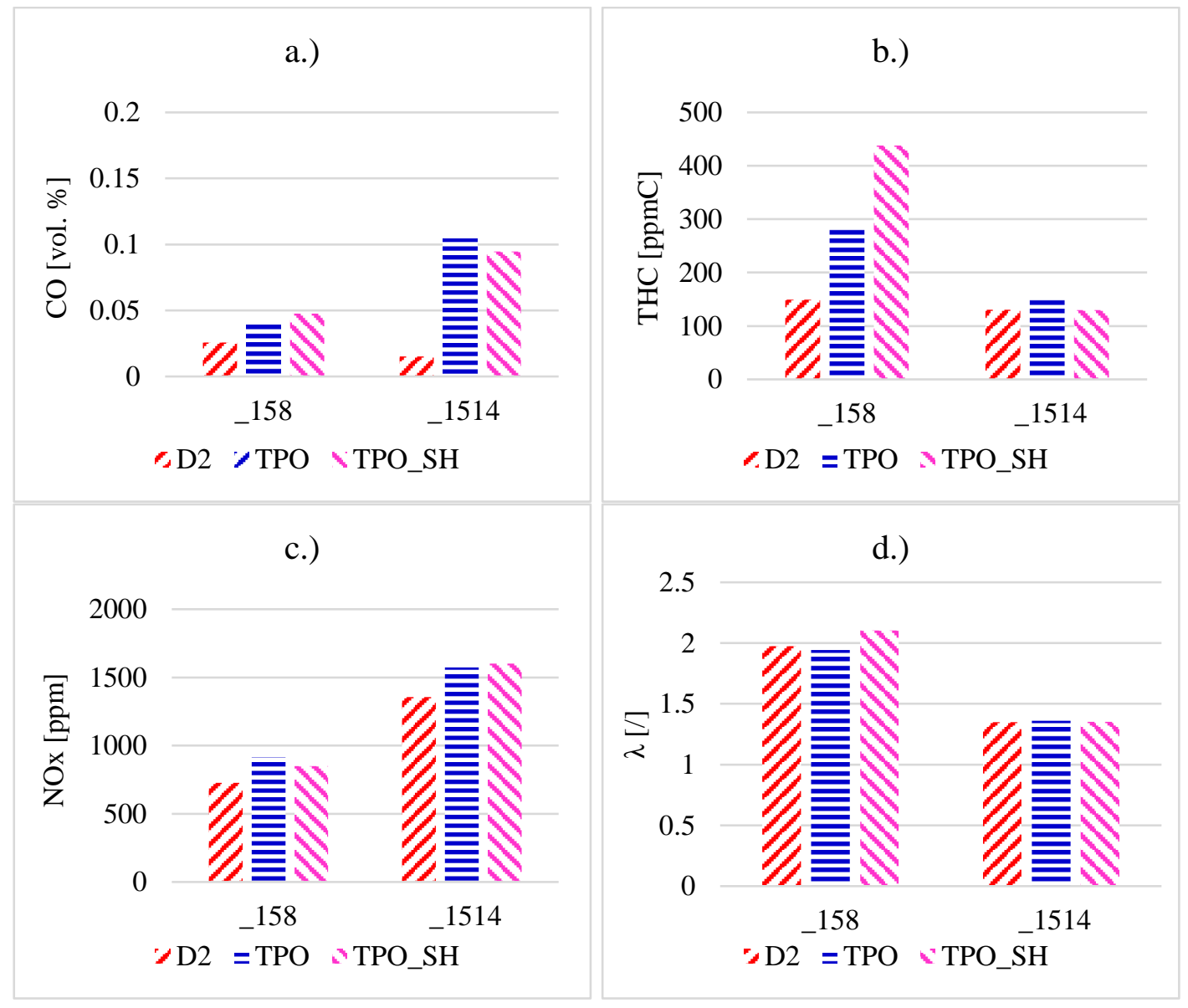

Fig. 4: a.) CO emissions, b.) THC emissions, c.) NO emissions and d.) lambda for operating point at 1500 rpm, 80 (denoted by_158) and 140 Nm (denoted by_1514) for D2 and TPO with original and shifted pilot injection. 
487 Fig. 4 reveals that emissions feature different trends at the medium load (1500 rpm and 140 $488 \mathrm{Nm}$ ) compared to those at low load (1500 rpm and $80 \mathrm{Nm}$ ).

\section{THC emissions}

First, at $1500 \mathrm{rpm}$ and $140 \mathrm{Nm}$, the THC emissions (Fig. 4b) of the TPO are at a comparable level as THC emissions of the D2 at the same operating point, whereas at the same time they are significantly lower than THC emission of the TPO at $1500 \mathrm{rpm}$ and $80 \mathrm{Nm}$. This trend of THC emissions of the TPO in comparison to D2 is also in line with previous study [24]. The reasons for lower THC emissions of the TPO at $1500 \mathrm{rpm}$ and $140 \mathrm{Nm}$ compared to $80 \mathrm{Nm}$ are:

- The overall temperature levels are higher at $140 \mathrm{Nm}$, which is advantageous for ignition of low cetane number TPO and combustion of ignition resistant hydrocarbons.

- The main injection quantity is higher at $140 \mathrm{Nm}$, which increases the volume of incylinder charge that is hit by reacting mixture from main injection. Thus, a larger part of the pilot mixture, which was outside of flammability limits, can be ignited, which reduces the THC emissions that originate from pilot injection.

Marginally lower THC emissions of TPO_SH in comparison to TPO with original injection timing can be, contrary to $80 \mathrm{Nm}$ load case, attributed to shorter ignition delay of pilot injection (Fig. 4a), which reduces the entrapment of mixture into colder parts of the combustion chamber.

\section{CO emissions}

The CO emissions in Fig. 4a are in the case of $1500 \mathrm{rpm}$ and $140 \mathrm{Nm}$ higher than at $80 \mathrm{Nm}$ as presented also in similar study where pure TPO was utilized in Diesel engine [24]. Generally, they can be attributed to lower lambda values, as presented in Fig. 4d. Higher temperatures being a consequence of lower lambda values sufficiently dissociate and ignite hydrocarbons (leading to lower THC emissions above), but at the same time generate larger oxygen-deprived regions, giving way to generation of $\mathrm{CO}$. However, notable differences in $\mathrm{CO}$ emissions between the D2 and both TPO and TPO_SH cases might arise due to complex chemical composition of TPO, which contains a large amount of cycling hydrocarbons, acting as a soot precursors [57]. Soot is generated in the areas of rich mixture, whereas its oxidation to CO occurs later in the combustion process, which acts as a source of $\mathrm{CO}$ in the late expansion phase. This reasoning is also supported by higher soot emissions of TPO, measured in previous studies with straight TPO [12] and TPO-D2 blends [15]. Based on this data it can be considered that CO emissions of the TPO are slightly more sensitive to lambda values that D2.

\section{$N O_{x}$ emissions}

The $\mathrm{NO}_{\mathrm{x}}$ emissions for $1500 \mathrm{rpm}$ and $140 \mathrm{Nm}$ in Fig. 4c are increased in comparison to $80 \mathrm{Nm}$ load point, which was showed also in study by Murugan et al. [28]. This is again strongly linked to temperature levels in the combustion chamber, which are in the $140 \mathrm{Nm}$ case higher than in $80 \mathrm{Nm}$ case. At the same time, combustion chamber temperatures in $140 \mathrm{Nm}$ load point are also more similar for TPO and TPO_SH than in $80 \mathrm{Nm}$ load point. This contributes to very similar

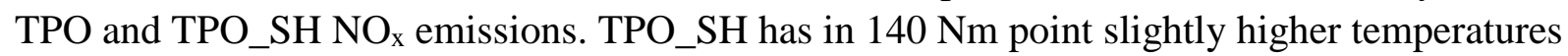
only in the pilot combustion phase, whereas the main combustion features roughly the same temperature as TPO with original injection timing. Consequently, the concentrations of TPO and TPO_SH NO $\mathrm{N}_{\mathrm{x}}$ emissions are also closer together than for $80 \mathrm{Nm}$. When comparing $\mathrm{NO}_{\mathrm{x}}$ emissions of the TPO to those of the D2, similar conclusions can be drawn as in $80 \mathrm{Nm}$ load case. In the interval of pilot injection, temperature levels are higher for D2, increasing thermal 
$530 \mathrm{NO}_{\mathrm{x}}$ component. Still, TPO with its high FBN content offsets this effect and even though the 531 temperatures are lower, $\mathrm{NO}_{\mathrm{x}}$ emissions are higher than those of D2 for both, TPO and TPO_SH.

\subsection{Fuel economy}

533 In this section, indicated fuel conversion efficiency (IFCE) for all analysed cases is presented and discussed. It is discernible from Fig. 5 that higher IFCEs are achieved at lower torque values for all cases, which can mainly be attributed to the ROHR traces. At low loads, ROHR peaks closer to the TDC indicating that higher share of fuel burns earlier in the expansion stroke yielding higher indicated efficiency.

At both loads, i.e. $80 \mathrm{Nm}$ and $140 \mathrm{Nm}$, IFCEs are lower when the TPO is utilized. This can mainly be reasoned by the longer ignition delay of the main injection compared to the D2 cases resulting in combustion mid-point shifted farther into the expansion stroke.

For the D2 fuel, omission of the pilot injection leads to slightly lower IFCE at $80 \mathrm{Nm}$ due to longer ignition delay of the main injection, whereas at $140 \mathrm{Nm}$ it leads to slightly higher IFCE, which can mainly be attributed to lower negative torque in the compression stroke as ROHR trace corresponding to main injection features similar mid-point in both cases. For the TPO case without PI, longer ignition delay of the TPO again results in lower IFCE at $140 \mathrm{Nm}$.

For both engine loads, shifting the PI of the TPO towards the TDC results in shorter ignition delay and slightly higher IFCE compared to the ECU injection strategy and the use of the TPO. In the case of shifted PI towards the TDC, increase in the IFCE can be achieved due to shorter ignition delay of the main injection of the TPO that allows for higher share of the injected fuel to be burned closer to the TDC.

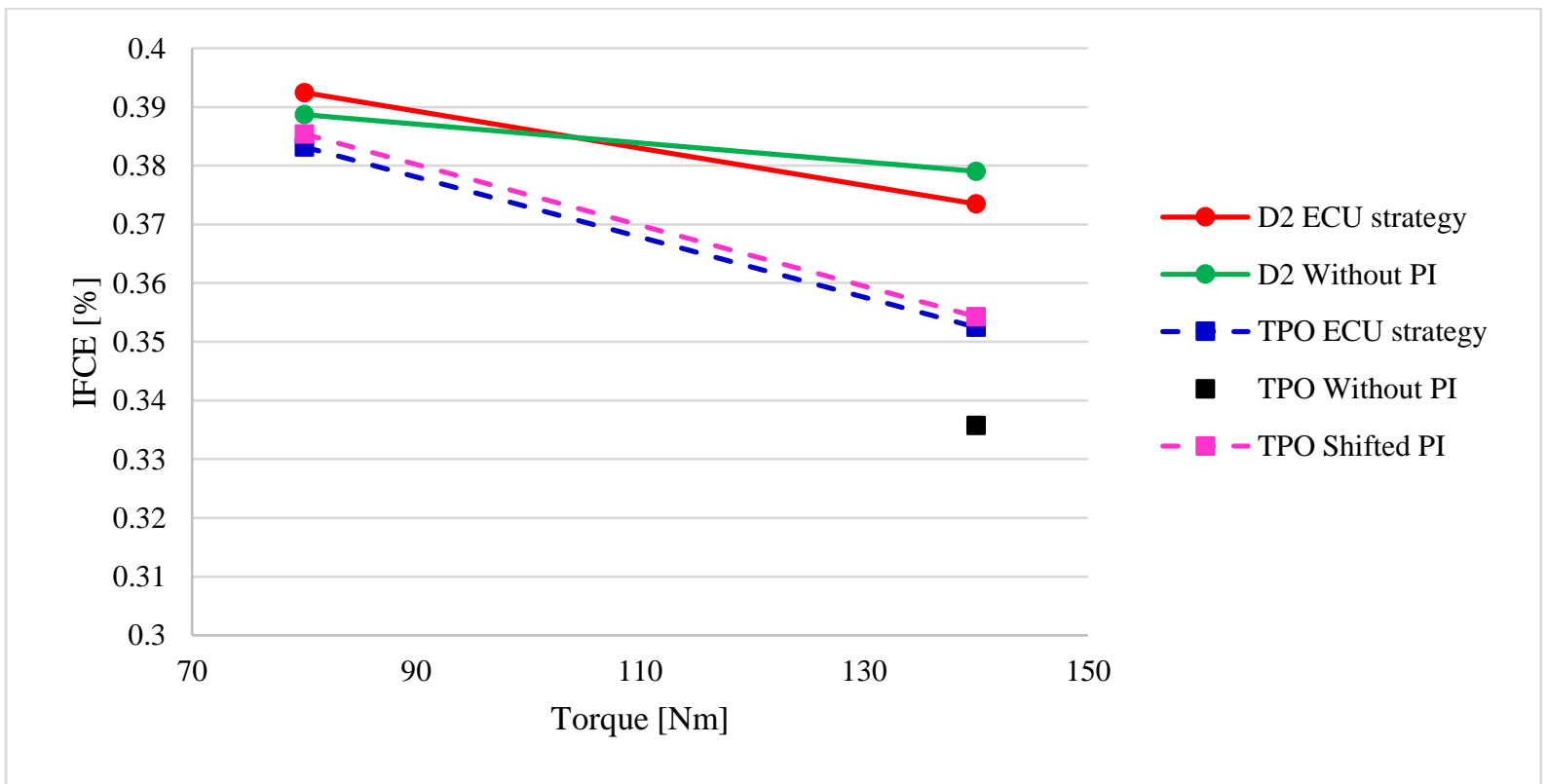

Fig. 5: Indicated fuel conversion efficiency for all analysed cases. 


\section{Conclusion}

556 The paper presents the foremost results of utilizing the pure TPO in a modern turbocharged and 557 intercooled Diesel engine without any hardware modifications or enhancements of fuel 558 properties. This goal is pursued as on one side the use of pure TPO is the most attractive option 559 in the case of energy recovery from waste and on the other side, its use in modern turbocharged 560 and intercooled Diesel engine without any hardware modifications lowers power plant cost and 561 boosts effective efficiency of the engines or CHP units.

562 Performed in-depth analysis of thermodynamic and emission response on various injection 563 strategies indicate that at least one pilot injection is needed for efficient combustion of pure 564 TPO fuel in modern turbocharged and intercooled Diesel engine, which presents a novelty in 565 comparison to existent methods for utilization of pure TPO in Diesel engines that mainly rely 566 on hardware modifications. Furthermore, the analysis suggests that Diesel-like combustion can 567 be achieved also at low-mid engine loads and speeds with pure TPO if pilot injection is retarded 568 in relation to original ECU injection strategy.

569 Emission levels which are comparable to the D2 ones can be achieved with the TPO and the 570 proposed injection strategy. This is particularly valid for medium engine loads, where moderately higher $\mathrm{NO}_{\mathrm{x}}$ emissions mirror the high share of FBN in TPO and marginally higher $\mathrm{CO}$ emissions suggest higher sensitivity of TPO to air-fuel ratio. Slight elevation of THC emissions was mainly attributed to differences in ignition delay of the TPO and to the fuel cetane number.

The significance of this study can be recognized in elaborating on the key guidelines on injection strategy and demonstration of the minimally invasive method to successfully use pure TPO in the modern turbocharged and intercooled Diesel engine. Although the findings of the study present an important advancement in expanding the operating range of the Diesel engine while using the TPO, the engine still needs to be started with the D2 fuel. 
582 [1] Kay D, Hill N, Newman D. The future of low-carbon cars and fuels 2013.

583 [2] Zhu L, Cheung CS, Huang Z. Impact of chemical structure of individual fatty acid esters on combustion and emission characteristics of diesel engine. Energy 2016;107:305-20. doi:10.1016/j.energy.2016.04.030.

[3] Pinzi S, Rounce P, Herreros JM, Tsolakis A, Pilar Dorado M. The effect of biodiesel fatty acid composition on combustion and diesel engine exhaust emissions. Fuel 2013;104:170-82. doi:10.1016/j.fuel.2012.08.056.

[4] E J, Liu T, Yang WM, Li J, Gong J, Deng Y. Effects of fatty acid methyl esters proportion on combustion and emission characteristics of a biodiesel fueled diesel engine. Energy Convers Manag 2016;117:410-9. doi:10.1016/j.enconman.2016.03.021.

[5] Chen LY, Chen YH, Hung YS, Chiang TH, Tsai CH. Fuel properties and combustion characteristics of jatropha oil biodiesel-diesel blends. J Taiwan Inst Chem Eng 2013;44:214-20. doi:10.1016/j.jtice.2012.09.011.

594

595

596

597

598

599

600

601

602

603

604

605

606

607

608

609

610

611

612

613

614

615

616

617

618

[6] Chauhan BS, Kumar N, Cho HM. A study on the performance and emission of a diesel engine fueled with Jatropha biodiesel oil and its blends. Energy 2012;37:616-22. doi:10.1016/j.energy.2011.10.043.

[7] Alptekin E. Emission, injection and combustion characteristics of biodiesel and oxygenated fuel blends in a common rail diesel engine. Energy 2017;119:44-52. doi:10.1016/j.energy.2016.12.069.

[8] Feng Z, Zhan C, Tang C, Yang K, Huang Z. Experimental investigation on spray and atomization characteristics of diesel/gasoline/ethanol blends in high pressure common rail injection system. Energy 2016;112:549-61. doi:10.1016/j.energy.2016.06.131.

[9] Valentino G, Corcione FE, Iannuzzi SE, Serra S. Experimental study on performance and emissions of a high speed diesel engine fuelled with n-butanol diesel blends under premixed low temperature combustion. Fuel 2012;92:295-307. doi:10.1016/j.fuel.2011.07.035.

[10] Sharma A, Murugan S. Potential for using a tyre pyrolysis oil-biodiesel blend in a diesel engine at different compression ratios. Energy Convers Manag 2015;93:289-97. doi:10.1016/j.enconman.2015.01.023.

[11] Przybyla G, Szlek A, Haggith D, Sobiesiak A. Fuelling of spark ignition and homogenous charge compression ignition engines with low calorific value producer gas. Energy 2016;116:1464-78. doi:10.1016/j.energy.2016.06.036.

[12] Bhaduri S, Contino F, Jeanmart H, Breuer E. The effects of biomass syngas composition, moisture, tar loading and operating conditions on the combustion of a tar-tolerant HCCI (Homogeneous Charge Compression Ignition) engine. Energy 2015;87:289-302. doi:10.1016/j.energy.2015.04.076.

[13] ACEA Pocket Guide 2016-2017 | ACEA - European Automobile Manufacturers' Association 2016:78.

[14] Weissman SL, Sackman JL, Gillen D, Monismith C. Extending the Lifespan of Tires: Final Report 2003:156.

[15] Martínez JD, Rodríguez-Fernández J, Sánchez-Valdepeñas J, Murillo R, García T. Performance and emissions of an automotive diesel engine using a tire pyrolysis liquid blend. Fuel 2014;115:490-9. doi:10.1016/j.fuel.2013.07.051. 
[16] Aydın H, İlkılıç C. Analysis of combustion, performance and emission characteristics of a diesel engine using low sulfur tire fuel. Fuel 2015;143:373-82. doi:10.1016/j.fuel.2014.11.075.

[17] Martínez JD, Puy N, Murillo R, García T, Navarro MV, Mastral AM. Waste tyre pyrolysis - A review. Renew Sustain Energy Rev 2013;23:179-213. doi:10.1016/j.rser.2013.02.038.

631

[18] Lah B, Klinar D, Likozar B. Pyrolysis of natural, butadiene, styrene-butadiene rubber and tyre components: Modelling kinetics and transport phenomena at different heating rates and formulations. Chem Eng Sci 2013:1-13.

[19] Roy C, Labrecque B, de Caumia B. Recycling of scrap tires to oil and carbon black by vacuum pyrolysis. Resour Conserv Recycl 1990;4:203-13. doi:10.1016/09213449(90)90002-L.

[20] Frigo S, Seggiani M, Puccini M, Vitolo S. Liquid fuel production from waste tyre pyrolysis and its utilisation in a Diesel engine. Fuel 2014;116:399-408. doi:10.1016/j.fuel.2013.08.044.

639

[21] Hariharan S, Murugan S, Nagarajan G. Effect of diethyl ether on Tyre pyrolysis oil fueled diesel engine. Fuel 2013;104:109-15. doi:10.1016/j.fuel.2012.08.041.

[22] Ilkiliç C, Aydin H. Fuel production from waste vehicle tires by catalytic pyrolysis and its application in a diesel engine. Fuel Process Technol 2011;92:1129-35. doi:10.1016/j.fuproc.2011.01.009.

[23] Koc AB, Abdullah M. Performance of a 4-cylinder diesel engine running on tire oilbiodiesel-diesel blend. Fuel Process Technol 2013;118:264-9. doi:10.1016/j.fuproc.2013.09.013.

[24] Vihar R, Seljak T, Rodman Oprešnik S, Katrašnik T. Combustion characteristics of tire pyrolysis oil in turbo charged compression ignition engine. Fuel 2015;150:226-35. doi:10.1016/j.fuel.2015.01.087.

[25] Wang WC, Bai CJ, Lin CT, Prakash S. Alternative fuel produced from thermal pyrolysis of waste tires and its use in a di diesel engine. Appl Therm Eng 2016;93:330-8. doi:10.1016/j.applthermaleng.2015.09.056.

[26] Sharma A, Murugan S. Investigation on the behaviour of a DI diesel engine fueled with Jatropha Methyl Ester (JME) and Tyre Pyrolysis Oil (TPO) blends. Fuel 2013;108:699_ 708. doi:10.1016/j.fuel.2012.12.042.

[27] Sharma A, Murugan S. Combustion, performance and emission characteristics of a DI diesel engine fuelled with non-petroleum fuel: A study on the role of fuel injection timing. J Energy Inst 2014;88:364-75. doi:10.1016/j.joei.2014.11.006.

[28] Murugan S, Ramaswamy MC, Nagarajan G. Assessment of pyrolysis oil as an energy source for diesel engines. Fuel Process Technol 2009;90:67-74. doi:10.1016/j.fuproc.2008.07.017.

[29] McNeil J, Day P, Sirovski F. Glycerine from biodiesel: The perfect diesel fuel. Process Saf Environ Prot 2012;90:180-8. doi:10.1016/j.psep.2011.09.006.

[30] Van De Beld B, Holle E, Florijn J. The use of pyrolysis oil and pyrolysis oil derived fuels in diesel engines for CHP applications. Appl Energy 2013;102:190-7. doi:10.1016/j.apenergy.2012.05.047.

[31] Shihadeh A, Hochgreb S. Diesel Engine Combustion of Biomass Pyrolysis Oils. Energy \& Fuels 2000;14:260-74. doi:10.1021/ef990044x. 
[32] Martinez JD, Rodriguez-Fernandez J, Sanchez-Valdepenas J, Murillo RR, Garcia T, Martínez JD, et al. Performance and emissions of an automotive diesel engine using a tire pyrolysis liquid blend. Fuel 2014;115:490-9. doi:10.1016/j.fuel.2013.07.051.

[33] Doğan O, Elik MB, Özdalyan B. The effect of tire derived fuel/diesel fuel blends utilization on diesel engine performance and emissions. Fuel 2012;95:340-6. doi:10.1016/j.fuel.2011.12.033.

[34] Quek A, Balasubramanian R. Liquefaction of waste tires by pyrolysis for oil and chemicals - A review. J Anal Appl Pyrolysis 2013;101:1-16. doi:10.1016/j.jaap.2013.02.016.

[35] SIST EN 590:2009/A101 - Automotive fuels - diesel - requirements and test methods. Slovenian Institute for Standardization; 2009.

[36] Hossain a. K, Davies P a. Pyrolysis liquids and gases as alternative fuels in internal combustion engines - A review. Renew Sustain Energy Rev 2013;21:165-89. doi:10.1016/j.rser.2012.12.031.

[37] Aydin H, Ilkiliç C. Optimization of fuel production from waste vehicle tires by pyrolysis and resembling to diesel fuel by various desulfurization methods. Fuel 2012;102:60512. doi:10.1016/j.fuel.2012.06.067.

[38] Bezaire N, Wadumesthrige K, Simon Ng KY, Salley SO. Limitations of the use of cetane index for alternative compression ignition engine fuels. Fuel 2010;89:3807-13. doi:10.1016/j.fuel.2010.07.013.

[39] ISO 12185:1996 - Crude petroleum and petroleum products -- Determination of density -- Oscillating U-tube method 1996:9.

[40] ASTM D4868 - 00(2010) - Standard Test Method for Estimation of Net and Gross Heat of Combustion of Burner and Diesel Fuels 2010.

[41] ASTM D6304 - 16e1 - Standard Test Method for Determination of Water in Petroleum Products, Lubricating Oils, and Additives by Coulometric Karl Fischer Titration 2016.

[42] EN 12916:2016 Petroleum Products - Determination Of Aromatic Hydrocarbon Types In Middle Distillates - High Performance Liquid Chromatography Method With Refractive Index Detection 2016:22.

[43] Murugan S, Ramaswamy MC, Nagarajan G. The use of tyre pyrolysis oil in diesel engines. Waste Manag 2008;28:2743-9. doi:10.1016/j.wasman.2008.03.007.

[44] ISO 3405:2011 - Petroleum products -- Determination of distillation characteristics at atmospheric pressure 2011:36.

[45] ISO 4264:2007 - Petroleum products - Calculation of cetane index of middle-distillate fuels by the four-variable equation 2012 .

[46] SIST EN 116:2015 - Determination of cold filter plugging point 2015:24.

[47] Katrašnik T, Trenc F, Oprešnik SR. A New Criterion to Determine the Start of Combustion in Diesel Engines. J Eng Gas Turbines Power 2006;128:928. doi:10.1115/1.2179471.

[48] Payri F, Luján JM, Martín J, Abbad a. Digital signal processing of in-cylinder pressure for combustion diagnosis of internal combustion engines. Mech Syst Signal Process 2010;24:1767-84. doi:10.1016/j.ymssp.2009.12.011.

[49] Kokjohn SL, Hanson RM, Splitter DA, Reitz RD. Experiments and Modeling of DualFuel HCCI and PCCI Combustion Using In-Cylinder Fuel Blending. SAE Int J Engines 
2009;2:24-39. doi:10.4271/2009-01-2647.

[50] AVL. Theory AVL BOOST. Gradec: AVL List GmbH; 2011.

[51] Prah I, Katrašnik T. Application of Optimization Techniques to Determine Parameters of the Vibe Combustion Model. Strojniški Vestn - J Mech Eng 2009;55:715-26.

718 [52] Hohenberg G. Experimentelle Erfassung der Wandwärme von Kolbenmotoren 1980.

[53] Polk AC, Carpenter CD, Srinivasan KK, Krishnan SR. An investigation of diesel-ignited propane dual fuel combustion in a heavy-duty diesel engine. Fuel 2014;132:135-48. doi:10.1016/j.fuel.2014.04.069.

[54] Maurya RK, Agarwal AK. Experimental investigation on the effect of intake air temperature and air-fuel ratio on cycle-to-cycle variations of HCCI combustion and performance parameters. Appl Energy 2011;88:1153-63. doi:10.1016/j.apenergy.2010.09.027.

[55] Siebers DL. Scaling liquid-phase fuel penetration in diesel sprays based on mixinglimited vaporization. SAE Tech Pap 1999:1-528. doi:10.4271/1999-01-0528.

[56] Klein-Douwel RJH, Frijters PJM, Seykens XLJ, Somers LMT, Baert RSG. Gas density and rail pressure effects on diesel spray growth from a heavy-duty common rail injector. Energy and Fuels 2009;23:1832-42. doi:10.1021/ef8003569.

[57] Williams PT, Taylor DT. Aromatization of tyre pyrolysis oil to yield polycyclic aromatic hydrocarbons. Fuel 1993;72:1469-74. doi:10.1016/0016-2361(93)90002-J. 


\section{Appendix}

736 Fig. 6 presents dependency between normalized $\mathrm{SO}_{2}$ emissions and normalized TPO fuel mass

737 flow, which was determined by Vihar et al. [24] and can be adopted for the used PSA light duty

738 engine. The coefficient of determination for the entire data set linear curve-fit, presented in the

739 Fig. 6, is calculated as 0.996 and therefore it can be acknowledged that presented data set linear

740 assumption between $\mathrm{SO}_{2}$ emissions and fuel mass flow.

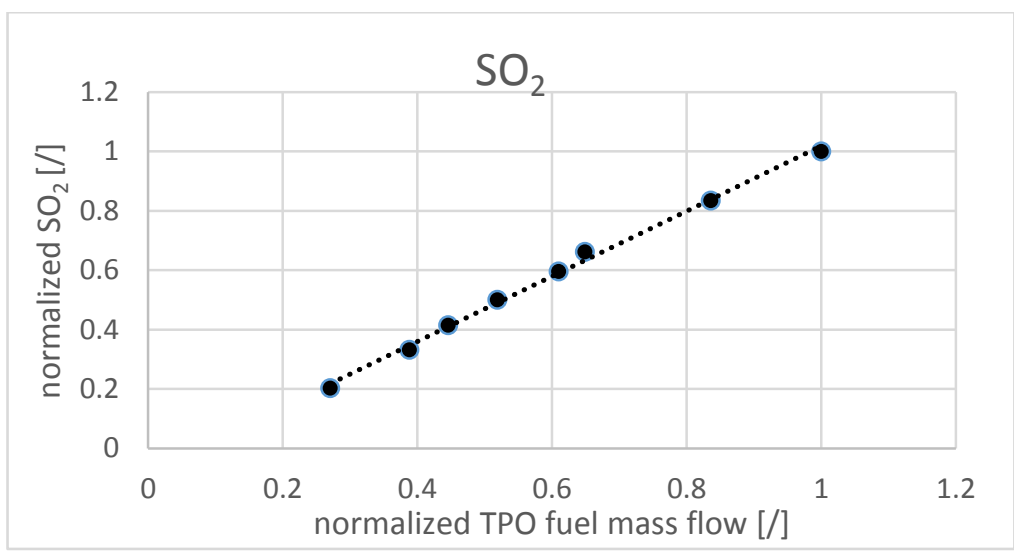

742 Fig. 6: Normalized $\mathrm{SO}_{2}$ emissions depending on normalized TPO fuel mass flow for MAN engine [24] 